\title{
Quantification of root reinforcement in bio-slope stabilization: laboratory and field studies
}

\author{
Apiniti Jotisankasa ${ }^{1, *}$, Danainut Taworn ${ }^{2}$, Nattasit Chumchey $^{2}$, and Jiraroth Sukolrat ${ }^{2}$ \\ ${ }^{1}$ Department of Civil Engineering, Kasetsart University, Jatujak, Bangkok, Thailand \\ ${ }^{2}$ Department of Highways, Ministry of Transport, Thailand
}

\begin{abstract}
Bio-slope stabilization is an environmentally friendly and sustainable technique for rehabilitation and maintenance of slope infrastructure. The processes in which these plants stabilize the slope, particularly root reinforcement, and evapotranspiration, mainly involved the unsaturated zone of the slope. Plants are also subjected to continuous change during the life time of bio-engineered slopes. This paper reports on recent studies on influence of roots on saturated and unsaturated soil properties, and suction effects on root reinforcement. These experimental results were then used to estimate the change in in-situ root reinforcement of biostabilized slope in the field. A new methodology based on the mini-rhizotron technique was proposed which linked the root-area ratio with root-reinforced strength and the factor of safety of the slope through laboratory-based relationships. This newly proposed method can be used to evaluate timebased performance of vegetated slope infrastructures in practice.
\end{abstract}

\section{Introduction}

Bio-slope stabilization or the use of plants to prevent erosion and shallow landslides has long been used for rehabilitation and maintenance of slope infrastructures around the world [1-2]. Owing to its sustainability, relatively low cost, and environmental value, this slope greening technique has become more popular among practitioners and researchers in the recent years [3-4]. There are different kinds of planting techniques which has been developed and effectively used, namely vetiver system, live stake, brushlayer, branch packing etc., most of which can be used in conjunction with engineering measures such as soil nail, gabion wall, geosynthetics and erosion control blanket.

Vetiver (Chrysopogon zizanioides) is one of the most widely used grasses in bioengineering application in tropical and sub-tropical climates [5-6]. When planted as hedgerows along the slope contour, Vetiver grass will act as a strong fence that considerably reduces the erosive force of runoff water, forming a so-called Vetiver System (VS). Its dense vertical fibrous root system can also penetrate 3-4 meters deep or more in favourable conditions, reinforcing the soil slope through additional shear strength.

Live staking or live poling is another effective bio-slope stabilization technique which is more commonly used in temperate zones and gaining more interest in tropical climates. By

\footnotetext{
* Corresponding author: fengatj@ku.ac.th
} 
burying woody fresh cuttings (from 12 up to $50 \mathrm{~mm}$ in diameter and 0.6 to $2 \mathrm{~m}$ long) by about $80 \%$ of its length deep into the ground, the live stakes or live poles will subsequently root out and act as a living soil anchor. A number of practical guidelines and case histories of live stake/pole application have been reported in the literature [2-3, 7-9].

In order to quantify the vegetation effects on slope stabilization work, in-depth understanding of root-soil mechanics are required especially in the variably saturated condition, as roots are normally present in the vadose zone in slopes. Various influences of vegetation on slope stability has been proposed by [10] suggesting that vegetation can exert both beneficial and adverse effects on mechanical and hydraulic properties. A major benefit in the mechanical aspect of plants on slope stability is via root soil reinforcement, which is considered as an additional soil strength or root cohesion [11-14]. Plants can provide additional slope stabilization effect further through transpiration, whereby soil moisture is extracted from the ground, thus increasing the soil suction and shear strength [15-16]. The roots can also affect soil's hydraulic conductivities, soil-water retention, and infiltration capacity in several opposing ways depending on root contents and growing stage $[15,17]$. Active growing roots tend to decrease permeability while decaying roots can increase macrovoid content, soil permeability, and infiltration into the soil. Despite that this increased infiltration is considered beneficial for erosion control, it could cause adverse effect on slope stability due to possible excessive induced pore-water pressure, especially for steep slopes ( $>$ $\left.60^{\circ}\right)$ [18].

Most previous studies on root reinforcement on slope stability only considered the root effects at a particular time, while in fact plants are in a continuously changing state throughout the design life of a bio-engineered slope. This study presents a new methodology to link the laboratory test results with field measurement of root contents using a nondestructive method, called mini-rhizotron, in order to quantify the current condition of root reinforcement. Selected laboratory results highlighting the root effects on unsaturated shear strength, and suction-effects on root reinforcement. A case study of a bioengineered slope along highway route no 44 in Southern Thailand is presented in order to illustrate the field technique.

\section{Laboratory test results on root-reinforced soils}

\subsection{Root reinforced soil strength}

A simplified model for shear strength of root-reinforced soil in a variably saturated state can be expressed as follows;

$$
\tau=c^{\prime}+\left(\sigma_{n}-u_{a}\right) \tan \phi^{\prime}+c_{s}+c_{r}
$$

where $c^{\prime}$ is the effective cohesion intercept of non-reinforced soil, $\sigma_{n}$ is normal stress, $u_{a}$ is pore-air pressure (normally equal to zero for soil near root zone), $\phi^{\prime}$ is the effective angle of friction of non-reinforced soil, $c_{s}$ is the cohesion due to suction, and $c_{r}$ is the cohesion due to roots. The cohesion due to suction, $c_{s}$, can be estimated as a function of suction and a normalized wetted area index around soil particles, which can be expressed in several forms [19-21] as follows;

$$
c_{s}=\chi\left(u_{a}-u_{w}\right) \tan \phi^{\prime}
$$

where $u_{w}$ is pore-water pressure, $\left(u_{a}-u_{w}\right)$ is the soil matric suction, and the Bishop's parameter, $\chi$, represents the effective wetted area over which the soil suction effectively 
contributes to shear strength. The parameter $\chi$ can be approximated to be equal to degree of saturation.

According to [12], the cohesion due to roots, $c_{r}$, can be expressed as follows;

$$
c_{r}=\sigma_{t}\left(\frac{A_{R}}{A}\right)[\sin \theta+\cos \theta \tan \phi]
$$

where;

$\sigma_{t}=$ the mobilized tensile stress of root fibers developed at the shear plane;

$\frac{A_{R}}{A}=$ the root area ratio: $A_{R}$ is the root area and $A$ is the total area of soil; and

$\theta=$ the angle of shear distortion in the shear zone.

This model indicates that shearing of the root-soil composite induces tensile stress in the root fibers which manifest itself into an increase in shear strength. Previous studies [2, 1214] suggested that the mobilized tensile stress is not necessarily equal to the tensile strength of the soil, $T_{r}$, since the roots did not necessarily always fail in tension, and normally experienced several failure modes, namely fibre break, fibre stretch, and fibre slip. As also shown in [13], the mobilized tensile stress of roots can be significantly influenced by the suction level of the soil and thus the model proposed for unsaturated root cohesion needs to consider these aspects appropriately.

The root area ratio, $\frac{A_{R}}{A}$, can vary significantly with space and time depending on the plant species, the relative location in slope, growth, and plant succession stage. Therefore, in practice, a semi-empirical model for root reinforcement is normally used which can be obtained based on results from either in-situ or laboratory direct shear tests as follows;

$$
\begin{aligned}
& c_{r}=a\left(\rho_{R}+b\right) \\
& c_{r}=k_{1}\left(\frac{A_{R}}{A}\right)+k_{2}
\end{aligned}
$$

where $\rho_{R}$ is the root biomass per unit volume of soil, $\mathrm{kg} / \mathrm{m}^{3}$, and $a, b, k_{1}, k_{2}$ are empirical constants which are species- and soil type-specific and dependent on test conditions. A recent study by [13] highlighted the influence of suction on these empirical constants and will be explained in the following. Notably, the relationship between root cohesion and root area ratio can used to estimate the root cohesion in the field based on field measurements of root area ratio.

The material used in this study by [13] was a clayey sand, classified as SC according to the Unified Soil Classification System taken from a cut slope along Highway no. 44 in Krabi province, Southern Thailand. The slope was located in a quaternary deposit near the foot of sandstone and limestone hills. This type of material is commonly found in highway constructions in the tropics. The study involved large direct shear testing of samples $(290 \mathrm{~mm}$ diameter) reinforced using Jatropha curcas live stake at two suction levels (zero and $23 \mathrm{kPa}$ ). Figure 1 shows the large direct shear apparatus and the specimens with Jatropha live stake. The specimens were contained in transparent acrylic molds and planted with live stake grown for different periods (up to 270 days). The specimens of various root contents were then sheared in order to obtain the variation between shear strength with root content. Figure 2 shows an example of a root photo as appearing from the side and root specimen. Dry biomass of the live stake and fibrous roots were also determined after the shearing test was completed. Root area ratios were then calculated from the root photos as apparent on the sample side using Matlab as follows;

$$
R A R_{\text {side }}=\frac{A_{R}}{A}=\frac{\text { Number of root pixels }}{\text { Total number of pixels }}
$$




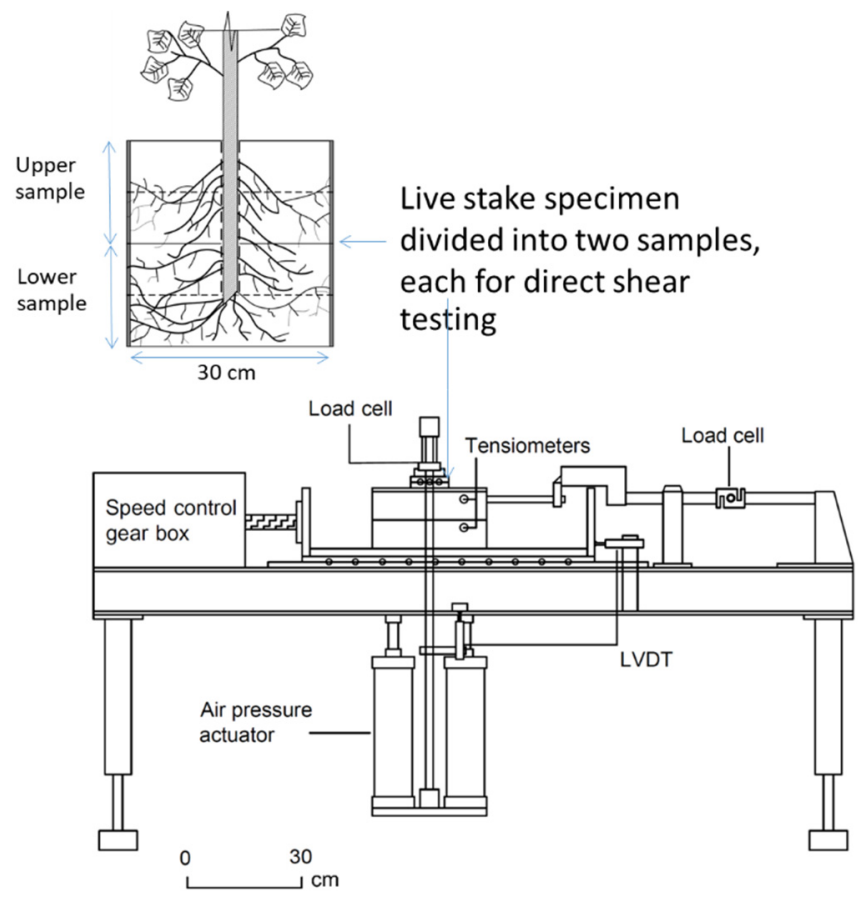

Fig. 1. Live stake specimen and the large direct shear apparatus, modified from [13]
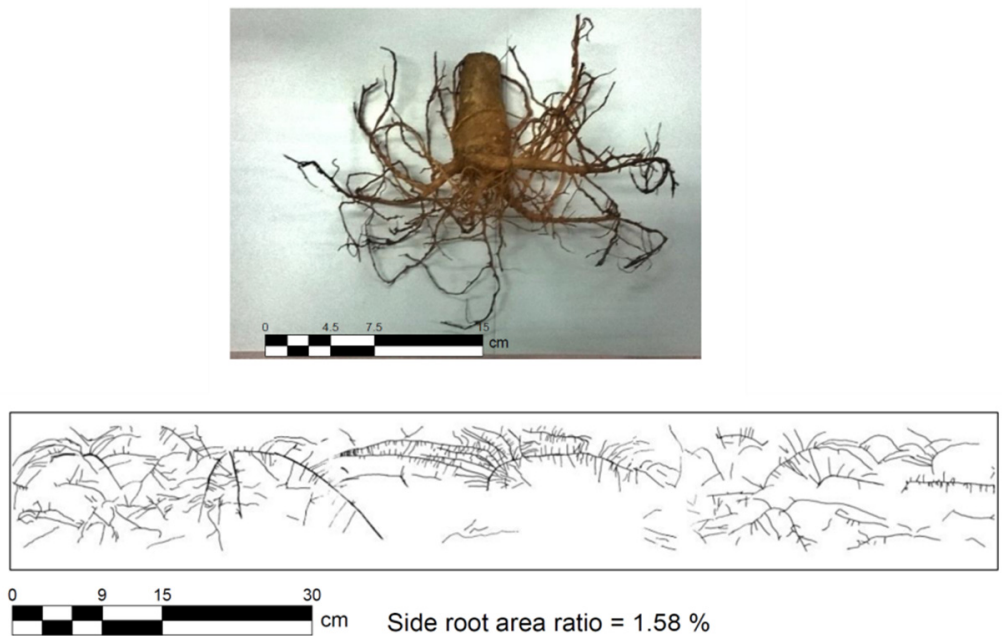

Fig. 2. Examples of roots obtained after shear test and the root pattern observed on the side of acrylic mold (sample SRL2)

Figure 3 shows the relationship between the total dry biomass (live stake + fibrous roots), fibrous roots dry biomass, and side area ratio. It can be seen that there is a better correlation between the fibrous root biomass and side area ratio than the total biomass and side root area ratio. It has been concluded by [13] that the fibrous root contents play a more significant role on improving soil shear strength than the live stake alone (without fibrous roots). 

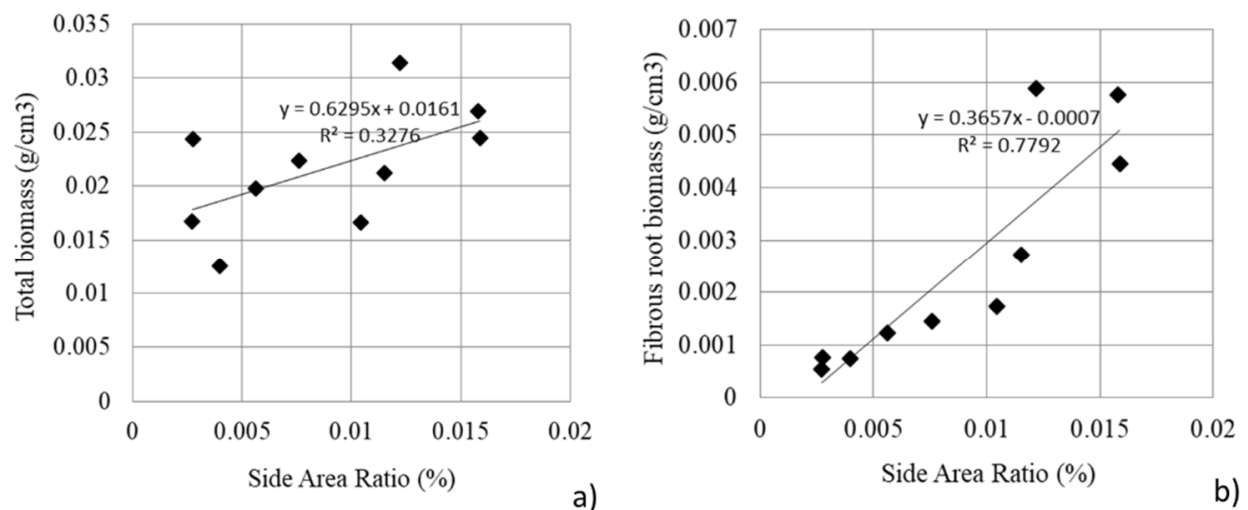

Fig. 3. Relationships between a) total dry biomass (live stake + fibrous roots) and side area ratio and

b) fibrous roots dry biomass and side root area ratio
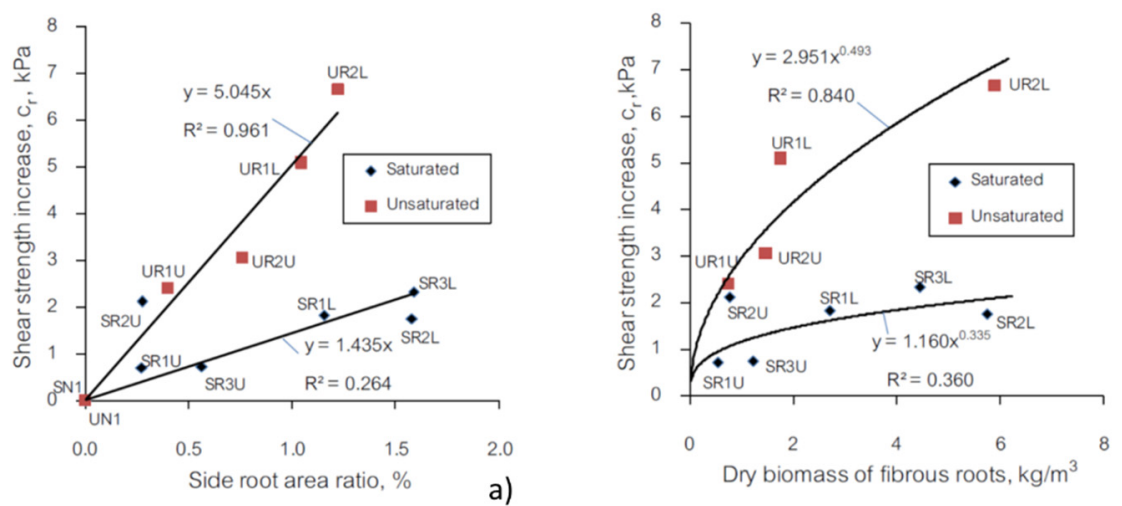

Fig. 4. Relationships between a) total dry biomass (live stake + fibrous roots) and side area ratio and b) fibrous roots dry biomass and side root area ratio, modified from [13]

The root cohesion, $c_{r}$ was calculated as the difference between measured ultimate strengths of root-reinforced soil and non-reinforced soil (Equation 1) and then plotted against the root contents as shown in Figure 4. Evidently, the root cohesion linearly increases with side root area ratio. When plotted against dry biomass of fibrous roots, the increase in root cohesion with roots was slightly nonlinear. Importantly, the rate of increase in $c_{r}$ also depends on saturation condition, and could be reduced by a factor of 3.5 if the conditions change from unsaturated (at about $23 \mathrm{kPa}$ suction) to fully saturated. At least for Jatropha live stake, the root cohesion, $c_{r}$, not only depends on the root content but also on the soil suction condition. Further details on the mechanism of suction-dependent root reinforcement are explained in [13].

\subsection{Root tensile strengths}

The tensile strength of Jatropha roots under different suction conditions were also investigated by [13]. The main findings will be presented here to highlight the influence of suction on root tensile strength. Three kinds of root specimens were tested. The first ones were those fibrous roots from large direct shear specimens, exhumed by washing out the soil particles around it, after completing their large direct shearing test. The second group was 
the intact root samples (not from sheared specimens) that had been soaked in water for three days. The third group were intact roots equilibrated to a total suction of approximately 39,300 $\mathrm{kPa}$, using isopiestic technique, or a vapor equilibrium method whereby the root specimens were hanged above a saturated $\mathrm{NaCl}$ solution until the mass became constant. The purpose of these tests was to determine the range of possible variations in root tensile strength with suction.

Figure 5 showed the tensile strength tests on Jatropha roots, indicating the smaller roots were of lower tensile strength and lower modulus. The drier roots had higher tensile strength. The roots collected after shear testing however had much smaller strength than the intact roots had. This indicated the tensile yielding of the roots during the reinforced soil shearing. The moduli of elasticity also decreased with root diameter and appeared to be higher in drier conditions. The roots from sheared soaked sample were of higher moduli than intact soaked roots, yet having lower tensile strength. It can be explained that the roots from sheared samples had already been tensioned during shearing, and thus the reloaded roots would show a stiffer response than that of the first loading (as in intact roots).
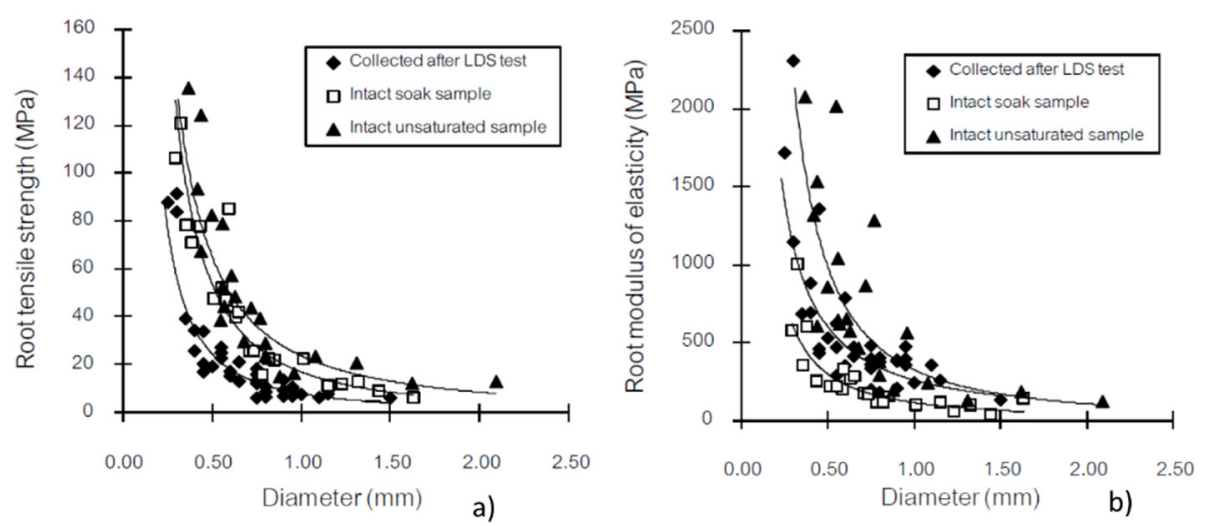

Fig. 5. Tensile strength and Modulus of Elasticity of Jatropha roots, modified from [13]

\section{Field evaluation of time-dependent root contents and root reinforcement}

A bioengineered test slope was constructed along Highway no. 44 in Krabi province, Southern Thailand using Jatropha live stakes as shown in Figure 6. A minirhizotron was installed in the middle of the slope to a depth of $0.9 \mathrm{~m}$ in order to monitor the changing root content with time. Mini-rhizotrons are transparent tubes (plastic or glass) installed in the soil near plants. A downhole camera can be used to take pictures of the roots outside of the wall tubes. The minirhizotron was installed at a distance of about $15-20 \mathrm{~cm}$ away from the live stake which was intended to be as close as possible to the radius of the mold used in the large direct shear test by [13]. It is noted that minirhizotron is a non-destructive method normally used to track the change in roots with time in plant studies [22]. The planting at this studied slope was finished in 01-Dec-2012. Minirhizotron studies were then conducted in 27-Mar2013 and 16-Aug-2013. Figure 7 shows the photographs of the slopes at these two stages. The root sketches at the side of the wall tube for the two periods are shown in Figure 8. 


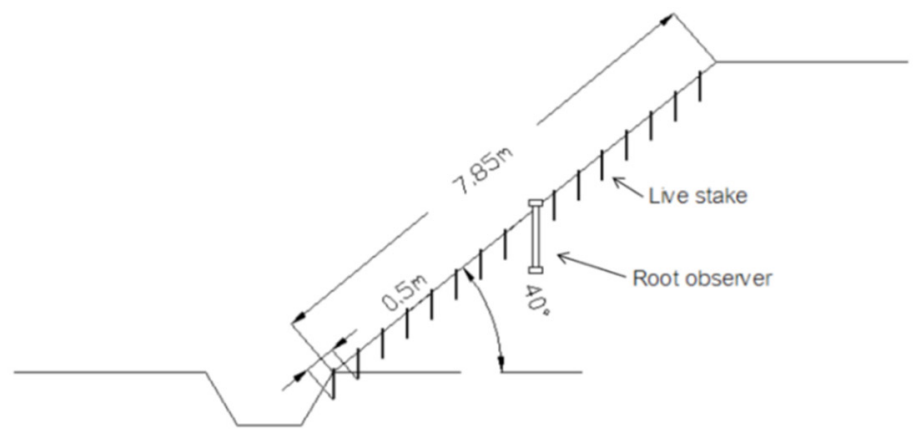

a)

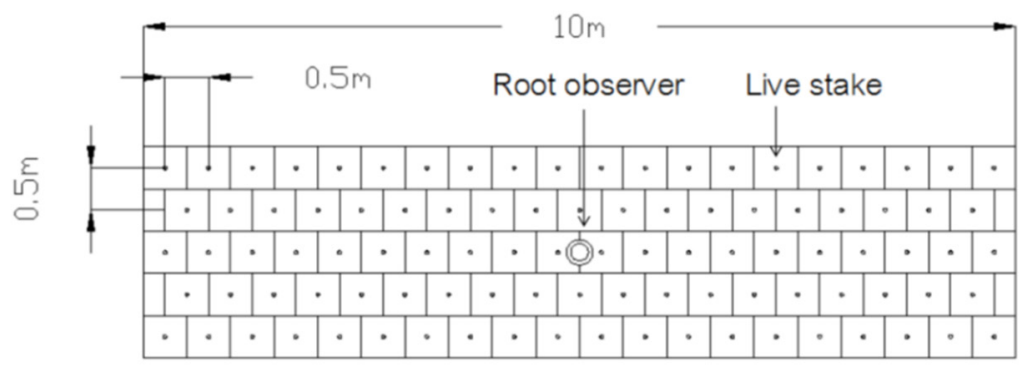

b)

Fig. 6. Bioengineered test slope using Jatropha live stake a) cross-section, b) plan

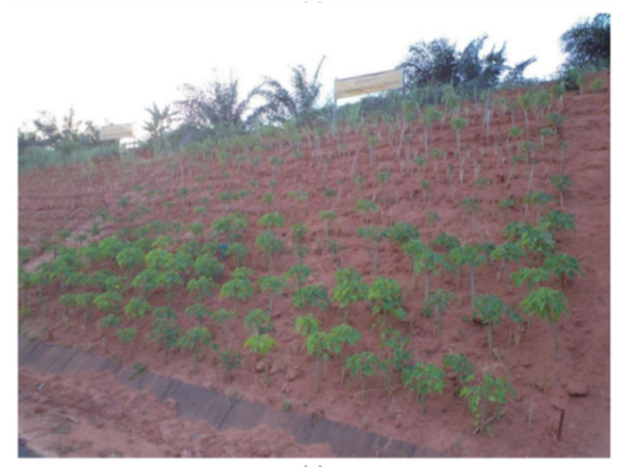

a)

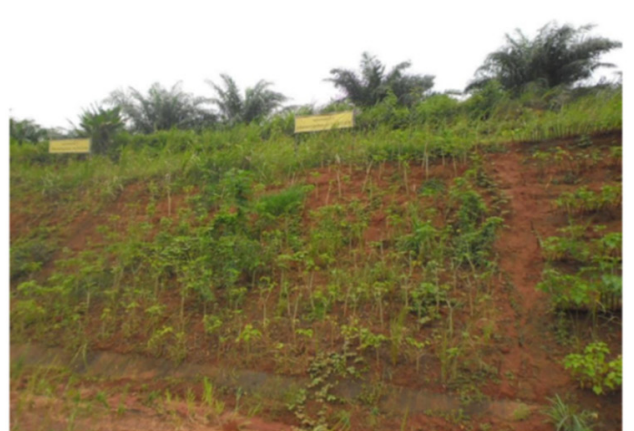

b)

Fig. 7. Photographs of bioengineered test slope a) $27 / 03 / 2013$, b) $16 / 08 / 2013$ 

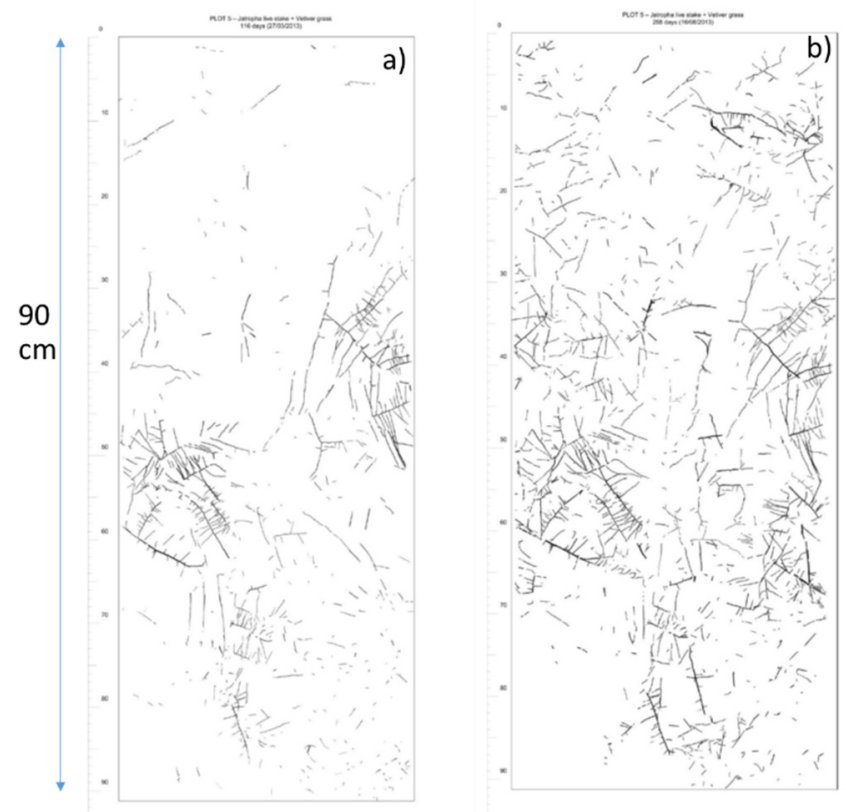

Fig. 8. Sketches of roots in a minirhizotron for the bioengineered test slope a) $27 / 03 / 2013$, b) $16 / 08 / 2013$

The sketches of roots were then analysed using a Matlab image analysis code to determine the distribution of root area ratio with depth as shown in Figure 9. The root area ratio increased over the five-month period from March 2013 to August 2013. These distributions in root area ratio, $R A R_{\text {side }}$, were then used to estimate the root cohesion, $c_{r}$. Distribution in the slope using the relationship between $R A R_{\text {side }}$ and $c_{r}$ (Figure 4) in both saturated and unsaturated conditions at two different periods are shown in Figure 10.
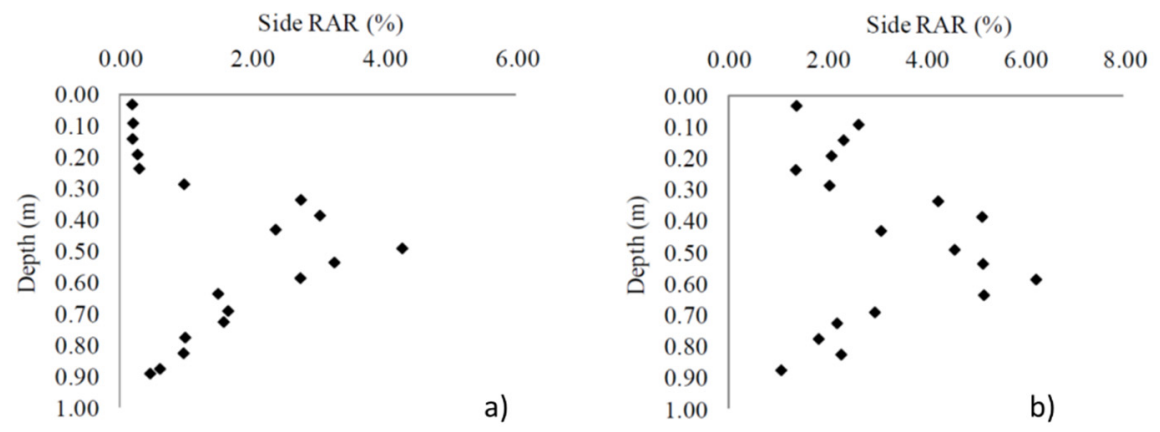

Fig. 9. Side root area ratio in a minirhizotron for the bioengineered test slope a) 27/03/2013, b) $16 / 08 / 2013$ 

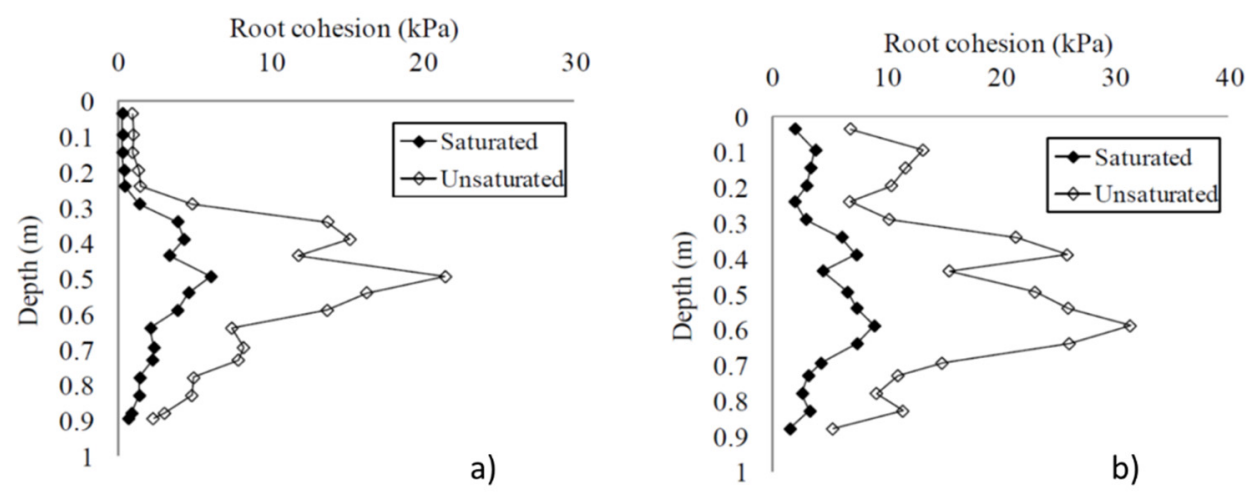

Fig. 10. Estimated root cohesion for the bioengineered test slope a) $27 / 03 / 2013$, b) 16/08/2013

The root cohesion was then used as an input in the infinite slope equation to estimate the factor of safety, F, of the slope as follows.

$$
\mathrm{F}=\frac{c_{r}+c^{\prime}+c_{S}+\left(\gamma \cdot z \cdot \cos ^{2} \beta\right) \tan \phi^{\prime}}{\gamma \cdot z \cdot \sin \beta \cdot \cos \beta}
$$

Where $\gamma$ is the soil unit weight, $z$ is the depth of failure, and $\beta$ is the slope angle. It should be noted that the infinite slope model was used as a first approximate assuming that the failure of this slope was of shallow type. Other types of failure surface can be employed in the future when more information on root distribution along the slope is available. Based on the root cohesion distributions, factor of safety distribution with depth were calculated as shown in Figure 11 for both unsaturated and saturated conditions. It can be seen that in unsaturated conditions (assuming $23 \mathrm{kPa}$ suction), both the non-reinforced and reinforced slope appeared to be stable (FS $>1.5)$. However, in saturated conditions (assuming zero pore water pressure or seepage flow angle being vertical), the roots were most effective in improving the factor of safety around the depth of 0.5 meter, where the root content was the highest. The nonreinforced saturated slope would fail at around this depth while the reinforced slope would still be stable. As the roots still did not reach a depth of about 0.9 meter, the root area ratio and root cohesion was relatively small in that range, giving a minimal increase in factor of safety at this depth.

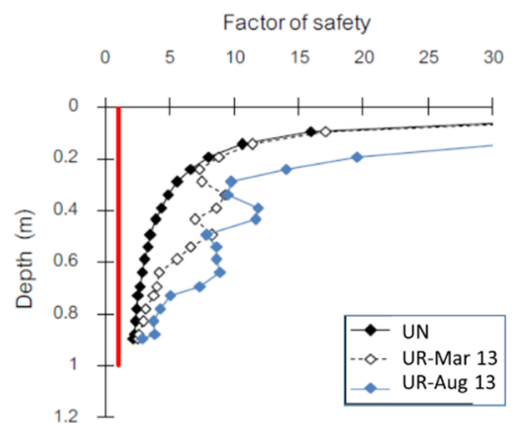

a)

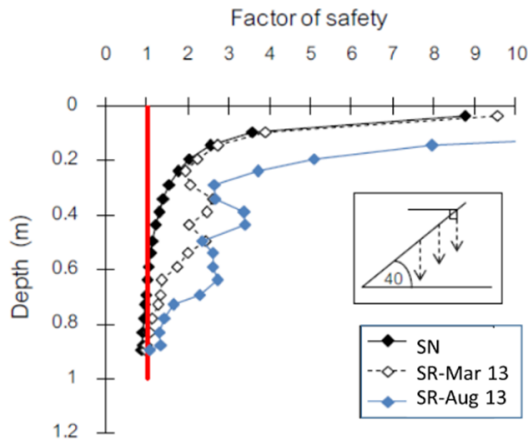

b)

Fig. 11. Estimated factor of safety for the test slope a) Unsaturated slope b) Saturated slope, for nonreinforced condition (UN \& SN) and for reinforced conditions (Mar-2013 \& Aug-2013) 


\section{Conclusions}

Plant roots are normally present in variably saturated zones and also subjected to continuous change during the life time of bio-engineered slopes. This paper reports on recent studies on the influence of Jatropha roots on saturated and unsaturated soil properties, and suction effects on root reinforcement in the laboratory. These experimental results were then used to estimate the field root reinforcement based on minirhizotron study. The following conclusions can be drawn.

- The root cohesion increases with side root area ratio and fibrous root biomass. The rate of increase in root cohesion also depends on saturation condition, and could be reduced by a factor of 3.5 if the suction was reduced from $23 \mathrm{kPa}$ to $0 \mathrm{kPa}$. The drier Jatropha roots were of higher root tensile strength. The roots collected after shear testing had been tensioned during shearing and thus showed a much smaller strength than the intact roots.

- Minirhizotron can be used to track the change in root area ratio with time in a bioengineered slope and thus can be used to estimate the root cohesion and factor of safety of the slope at different times. A case study of slope along Highway no. 44 in Southern Thailand was used to illustrate this methodology. It was shown that, 8 months after planting, the roots were most effective in improving the factor of safety of the slope in saturated condition (assuming zero pore water pressure or seepage flow angle being vertical) at the depth of around 0.5 meters, where the root content was the highest. This technique can be used to track the time-dependent change in performance of bio-slope stabilization in the future.

The authors gratefully acknowledge the support provided by the Department of Highways, National Research Council of Thailand, Chaipattana Foundation, and Kasetsart University Research and Development Institute (KURDI), Thailand.

\section{References}

1. N. J. Coppin, D. L. Barker, I. Richards, Use of vegetation in civil engineering (Butterworths, London, 1990)

2. D.H. Gray, R.B. Sotir, Biotechnical and Soil Bioengineering Slope Stabilization A Practical Guide for Erosion Control (John Wiley \& Sons, 1996)

3. W. Goldsmith, D.H. Gray, J. McCullah, Bioengineering Case Studies Sustainable Stream Bank and Slope Stabilization (Springer, pp. 2014)

4. M.W. Bo, M. Fabius, A. Arulrajah, S. Horpibulsuk, Environmentally friendly slope stabilization using a soil nail and root system in Canada. Ground Improvement Case Histories: Chemical, Electrokinetic, Thermal and Bioengineering Methods 629-654 (2015)

5. D. Hengchaovanich, Vetiver grass for slope stabilization and erosion control, with particular reference to engineering applications. Technical Bulletin No. 1998/2. Pacific Rim Vetiver Network (1998)

6. P. Truong, T.T. Van, E. Pinners, The vetiver system for slope stabilization an engineer's handbook (2008)

7. T.H. Wu, C.M. Kokesh, B.R. Trenner, P.J. Fox, Use of Live Poles for Stabilization of a Shallow Slope Failure, J. Geotech. Geoenviron. Eng., 140, 1-13 (2014) 
8. B.B.K, Huat, S. Mafian, S. Kazemian, M. Barghchi, Assessment of indigenous plants for live pole applications in slope stability of Malaysia," Australian Journal of Basic and Applied Sciences, 5, 9, 22-27 (2011)

9. A. Jotisankasa, Application of local plant species for live stake as a bio-slope stabilization method in Thailand, Proc. of 4th Tokyo Tech-KU Joint Seminar on Infrastructure Development, Tokyo Institute of Technology, O-okayama Campus, Tokyo, Japan, 145-150 (2013)

10. D.R. Greenway, Vegetation and slope stability. Slope stability. (Wiley, New York 1987)

11. N.S. Nilaweera, P. Nutalaya, Role of tree roots in slope stabilization. Bulletin of Engineering Geology and the Environment 57, 4, 337-342 (1999)

12. T. H., Wu, Root reinforcement of soil: review of analytical models, test results, and applications to design, Canadian Geotechnical Journal 50, 259-274 (2012)

13. A. Jotisankasa, D. Taworn, Direct Shear Testing of Clayey Sand Reinforced with Live Stake. Geotechnical Testing Journal 39 (4), 608-62 (2016)

14. M. Schwarz, F. Preti, F. Giadrossich, P. Lehmann, D. Or, Quantifying the role of vegetation in slope stability: A case study in Tuscany (Italy). Ecological Engineering, 36(3), 285-291 (2010)

15. J. J. Ni, A. K. Leung, C.W.W. Ng, P. S. So, Investigation of plant growth and transpiration-induced matric suction under mixed grass-tree conditions. Canadian Geotechnical Journal, 54(4), 561-573 (2017)

16. B. Fatahi, H. Khabbaz, B. Indraratna, Bioengineering ground improvement considering root water uptake model. Ecological Engineering, 36(2), 222-229 (2010)

17. A. Jotisankasa, T. Sirirattanachat, Effects of grass roots on soil-water retention curve and permeability function. Canadian Geotechnical Journal, 54(11), 16121622. (2017)

18. A. Jotisankasa, W. Mairaing, S. Tansamrit, Infiltration and stability of soil slope with vetiver grass subjected to rainfall from numerical modeling. Proc. of the 6th Int. conf. on unsaturated soils, UNSAT 2014, Unsaturated Soils: Research \& Applications Sydney Australia, 1241-1247 (2014)

19. A. W. Bishop, I. Alpan, G. E. Blight, I. B. Donald, Factors controlling the strength of partly saturated cohesive soils, Proc., Res. Conf. on Shear Strength of Cohesive Soils, Univ. of Colorado, Boulder, 503-532. (1960)

20. D. G. Fredlund, H. Rahardjo, Soil mechanics for unsaturated soils (Wiley, New York 1993)

21. N. Lu, W. J. Likos, Suction stress characteristic curve for unsaturated soil, J. Geotech. Geoenviron. Eng., 1322, 131-142 (2006)

22. M.G. Johnson, D.T. Tingey, D.L. Phillips, M.J. Storm, Advancing fine root research with minirhizotrons, Environmental and Experimental Botany, 45, 263289 (2001) 